\title{
SOBRE SEGURIDAD JURÍDICA Y DERECHO PENAL ECONÓMICO*
}

\section{ON SECURITY AND ECONOMIC CRIMINAL LAW}

\section{SUR SÉCURITÉ ET DROIT PÉNAL ECONOMIQUE}

\section{Enrique Bacigalupo **}

Señor Rector, Autoridades Académicas, Señoras y Señores:

Recibir el título de Doctor honoris causa de la Universidad de Chile es una distinción para mí incomparable. Por tres razones: porque esta Universidad es la Universidad de Andrés Bello, que simboliza en América Latina la más genuina tradición de la cultura universal; además, porque también mi Maestro, D. Luis Jiménez de Asúa, recibió el mismo título y, también, porque la Universidad de Chile acogió en 1966, con extraordinaria generosidad académica, a muchos profesores argentinos violentamente expulsados de sus cátedras.

Por otra parte, mi vínculo espiritual con la Universidad de Chile va más allá de mi actividad docente en el programa de postgrado que ella desarrolla conjuntamente con el Instituto Universitario de Investigación José Ortega y Gasset. Se remonta al recuerdo del trato personal y científico de muchos años con penalistas chilenos como Luis Ortiz Quiroga, Alfredo Etcheberry y Enrique Cury, y con otros que lamentablemente ya no nos acompañan: Álvaro Bunster, Eduardo Novoa Monreal, Luis Cousiño Mc. Iver, Miguel Schweizer, Sergio Yánez, Francisco Grisolía, y Juan Bustos.

El capítulo de los agradecimientos es amplio. En primer lugar quiero expresar mi muy especial agradecimiento al Director del Departamento de Derecho Penal, Profesor Don Vivian Bullemore, con quien trabajamos desde hace años en el desarrollo del derecho penal económico y en la formación de jóvenes juristas, y al Señor Decano de la Facultad de Derecho, Prof. Roberto Nahum, con cuyo apoyo entusiasta hemos contado. Mi agradecimiento se extiende, además, a todos los colegas de la Facultad de Derecho y de la Universidad, que probablemente con más generosidad que justicia han aprobado la concesión del doctorado que hoy recibo.

\footnotetext{
* El equipo de redacción de la Revista señala que se ha mantenido el formato original de la clase magistral, a fin de reflejar fielmente su espíritu.

** Catedrático de Derecho Penal. Director del Seminario de Derecho Penal del Instituto Universitario de Investigación José Ortega y Gasset (Madrid).
} 
Con la venia del Sr. Rector, daré mi lección sobre el tema: "Seguridad jurídica y derecho penal económico".

\section{- I -}

En la tradición político-jurídica europea las ideas de seguridad y de libertad han estado vinculadas estrechamente con la legalidad. La legalidad es el medio con el cual un Estado de Derecho garantiza la libertad, porque la ley permite conocer los límites de la acción del Estado y el marco en el que las decisiones individuales solo dependen de la voluntad de la persona. Consecuentemente, la libertad presupone seguridad, y en especial, seguridad jurídica.

A la pregunta por la seguridad jurídica, en el sentido de la posibilidad de predecir la reacción del Estado a las conductas de los ciudadanos, es posible dar respuestas diversas, según el aspecto del problema del que se parta.

Los economistas y los sociólogos han subrayado el valor de la seguridad jurídica en el cálculo de las condiciones necesarias para decidir sobre las inversiones de capital en un determinado Estado. Su apreciación de la seguridad se apoya en datos empíricos, investigados sobre la base de encuestas demoscópicas y de la constatación de determinados factores sociales, principalmente la existencia de corrupción en el funcionariado y en las relaciones comerciales entre particulares. Es evidente que la posibilidad de obtener decisiones de las autoridades por medio de sobornos es un dato que pone en tela de juicio la vigencia del derecho. De la misma manera, los pagos de comisiones o las ventajas personales acordadas para la obtención de contratos perturban seriamente la competencia. Ello explica que, por ejemplo, tanto en Alemania ( 299 StGB) como en España (art. 286 bis CP), haya sido introducido en los códigos penales, un nuevo tipo penal que incrimina la corrupción entre particulares en las relaciones mercantiles.

Cuando se estudian los criterios de los economistas y de los sociólogos sobre la seguridad jurídica surge la sensación de que tales criterios se refieren a "estados de opinión" de las personas, relativos a la vigencia real del derecho en las relaciones cotidianas; dicho de otro modo, las ideas que dominan en la sociedad sobre la vigencia del derecho y, particularmente, sobre la aplicación imparcial de la legalidad vigente y, consecuentemente, respecto de la continuidad predecible de las decisiones judiciales y de las autoridades administrativas.

Los juristas tratan esta cuestión desde otra perspectiva. A los juristas les preocupan en primer término las condiciones de la seguridad jurídica como elemento constitutivo del propio sistema jurídico. Por lo tanto, les importa especialmente cuáles son las condiciones técnico-jurídicas del modelo ideal de legislación que garantizan la seguridad de su aplicación judicial y administrativa. 
En la tradición del derecho europeo democrático la legalidad está estrechamente vinculada a la existencia de un ordenamiento de normas escritas (sea que las haya producido un parlamento o que se deduzcan de precedentes judiciales con fuerza obligatoria) que rigen para el futuro y que permiten orientar la conducta de cada ciudadano. Por esta razón el TEDH ha establecido que cumple las exigencias del principio de legalidad del artículo 7 del Convenio Europeo de Derechos Humanos el derecho penal de los Estados que admiten delitos de common law, si estos están adecuadamente tipificados por la jurisprudencia de los tribunales y el marco penal está claramente delimitado ${ }^{1}$.

En el orden jurídico estatal, el derecho penal es el que, dentro de esa tradición, ha representado el límite más importante de la libertad y el que mayor significación acuerda a la legalidad. Desde la Declaración de los Derechos del Hombre y del Ciudadano de 1789 el principio de legalidad aparece en todas las constituciones modernas y en los tratados regionales sobre derechos fundamentales.

El principio de legalidad es, prácticamente, el único principio del derecho penal que aparece expresamente en los textos constitucionales. El otro gran principio del derecho penal moderno, el principio de culpabilidad, es básicamente una construcción dogmática, elaborada por la teoría y la jurisprudencia a partir de la dignidad de la persona y del derecho al libre desarrollo de la personalidad (la Constitución Española hace referencia a ambos en los artículos 10.1). Aunque ocasionalmente se le reconozca jerarquía constitucional, el principio de culpabilidad no es reconocido de la misma manera en todos los EE MM de la UE (por ej. en Francia), ni constituye una materia específica de la dogmática de los derechos fundamentales ${ }^{2}$.

Tampoco es tratado en la teoría penal como una manifestación de la función de garantía de la ley penal en el Estado de Derecho: se le considera como un principio de la politica criminal ${ }^{3}$ o como un límite de la intervención estatal mediante acciones preventivas ${ }^{4}$.

Los principios de legalidad y culpabilidad, no obstante su trascendencia, son en origen principios formales: no determinan el contenido de la ley penal ni

\footnotetext{
1 Confr. J. A. Frowein/W. Peukert, EMRK-Kommentar, $2^{\mathrm{a}}$ edición, 1996, p. 323. No es acertado considerar que el common law no es derecho escrito. Es derecho escrito por los jueces.

2 Confr. J. Pérez Royo, Curso de Derecho Constitucional, $3^{a}$ edición, 1996, pp. 277 y ss.; B. Pieroth/ B. Scblink, Grundrechte Staatsrecht II, $3^{a}$ edición, 1987, pp. 87 y ss.; K. Hesse, Grundzüge des Verfassungsrechts der BRD, 16. edición, 1988, pp. 144 y ss.

3 Así H-H. Jescheck/Th. Weigend, Lehrbuch des Strafrecht, AT, $5^{a}$ edición, 1996, pp. 23 y ss. Ver también: M. Köbler, Strafrecht, AT, 1997, pp. 71 y ss. y 347 y ss. En el mismo sentido en Italia: G. Marinucci/E. Dolcini, Diritto Penale, PG 2002, pp. 13 y ss.; G. Fiandaca/E. Musco, Dirittto Penale, PG 1990, pp. 19 y ss. y 154 y ss. En Francia el principio de culpabilidad no aparece entre las exigencias constitucionales de la ley penal, como límites al poder de incriminar: confr. J-H. Robert, Droit Pénal Général, $5^{a}$ edición, 2001, pp. 120 y ss.; J. Pradel, Droit Pénal Général, $12^{a}$ edición, 1999, pp.131 y ss.

4 Así C. Roxin, Strafrecht, AT I, $3^{a}$ edición, 1997, pp. 59 y ss.
} 
tampoco determinan el concepto de culpabilidad como presupuesto y fundamento de la medida de la pena. En la ciencia penal actual, sin embargo, el aspecto formal de estas garantías no agota la problemática constitucional del derecho penal. En las últimas décadas también han adquirido importancia constitucional las cuestiones materiales, como la "cantidad" de derecho penal constitucionalmente compatible con una sociedad democrática, una materia que por lo general es presentada simplificadamente, desde el punto de vista de la teoría del bien jurídico. En todo caso, actualmente no solo es importante la existencia de una ley escrita y previa. Importa también la calidad de la ley y la calidad de su aplicación. A la exigencia de ley (lex praevia), se han agregado la de ley determinada (lex certa) y la prohibición de extensión de su alcance a casos análogos (lex stricta).

Probablemente ninguna materia sea tan apropiada para una consideración comparativa como esta, porque el principio de legalidad es un valor esencial de la cultura jurídica moderna. Voy a ejemplificar con el derecho español vigente y en menor medida con el derecho alemán, pero los problemas que voy a tratar son generales. Tengo entendido que el derecho penal chileno está en vías de ser reformado y espero, de esta manera, contribuir, aunque sea muy modestamente, a la ingente tarea de esa reforma. Como señalaba Franz v. Liszt, la tarea de una reforma penal "es nacional (...)", pero "es al mismo tiempo en un cierto sentido internacional"5, porque, de la misma forma que la cultura de un país fluye dentro del movimiento general de la cultura, la cultura jurídica de los países es solo un miembro del desarrollo jurídico general.

No obstante su posición indiscutida en el orden jurídico, prácticamente todo lo concerniente al principio de legalidad tiene en la actualidad puntos de discusión sumamente importantes. Hace casi tres décadas que se viene denunciando la erosión que sufre este principio y sus dificultades para imponerse de manera satisfactoria.

Esta erosión se percibe también en el derecho penal económico, ámbito en el que el principio de legalidad está expuesto también, de hecho, a la relativización. Aquí el fenómeno se diferencia del que caracteriza al derecho penal internacional, que afecta fundamentalmente a la lex scripta, es decir a las fuentes del derecho penal. La relativización del principio de legalidad en el derecho penal económico se presenta en relación con la lex certa y con la lex stricta, es decir con la exigencia de determinación precisa de la conducta punible y con la prohibición de la analogía. Ni la lex praevia, ni la lex scripta se ven afectadas por la estructura de los tipos penales del derecho penal económico moderno.

5 Prólogo de la Vergleichende Darstellung des Deutschen und Ausländischen Strafrechts, AT, tomo II, 1905. 
Durante el último cuarto del siglo XX se registra una progresiva criminalización de diversos ámbitos de la vida mercantil y empresarial, que, tradicionalmente solo estaban sometidos a eventuales responsabilidades civiles. Menciono solo algunos ejemplos del derecho penal español vigente. El perjuicio grave causado al equilibrio de los sistemas naturales (art. $325 \mathrm{CP}$ ) o el perjuicio del equilibrio biológico (art. $333 \mathrm{CP}$ ) no eran punibles en el derecho penal clásico y así formulados son, como lo señala Roxin ${ }^{6}$, “demasiado vagos". La polución de un río, p. ej., estaba sometida -si existía suficiente conciencia social y política al respecto- a la responsabilidad civil por los daños patrimoniales o personales que pudiera producir. Solo el envenenamiento de las aguas era delito. El abuso del derecho de la mayoría de los accionistas en perjuicio de la minoría (art. $291 \mathrm{CP}$ ), la extralimitación del mandato por parte de sus administradores (art. $295 \mathrm{CP}$ ), salvo la llamada "apropiación" indebida de dinero (art. $252 \mathrm{CP}$ ), o el abuso de información privilegiada (art. $285 \mathrm{CP}$ ), la corrupción en las negociaciones particulares (art. 286 bis CP), los abusos de mercado en perjuicio de los precios resultantes de la competencia (art. $284 \mathrm{CP}$ ), entre otros, también eran cuestiones que afectaban, en todo caso, a la nulidad o validez de los actos jurídicos respectivos, sometidos también exclusivamente a la responsabilidad civil, lo mismo que ciertos incumplimientos de las medidas de seguridad en el trabajo o en la manipulación de materiales peligrosos. Paralelamente, los cambios tecnológicos en la vida económica han dado lugar a que los tradicionales delitos de estafa y de administración desleal hayan sido diversificados en una serie de tipos penales que, simplificando sus estructuras, extienden la protección del patrimonio a situaciones antes desconocidas (como el fraude de subvenciones, la estafa de crédito, la defraudación de la Seguridad Social, la obtención de prestaciones fraudulentas a través de aparatos automáticos, la estafa de inversiones o la estafa de computación).

No se trata ahora de poner en duda el merecimiento de pena de hechos de esta naturaleza, sino de observar la técnica del legislador en algunos de los nuevos tipos penales de este subsistema normativo.

Los delitos del derecho penal económico se diferencian de los del derecho penal clásico -en un número importante de casos- sobre todo por la "invisibilidad" y la "incorporeidad" de los elementos que los definen en la ley. Con invisibilidad quiero referirme a la preponderancia de los elementos normativos -en detrimento de los descriptivos- en la estructuración de los tipos penales. Incluso es de señalar el caso de ciertos elementos, tradicionalmente no considerados normativos, como la causalidad, que en la estructura de muchos tipos penales del derecho penal económico resultan especialmente complejos. Por ejemplo, en los delitos contra el medio ambiente o en el ámbito de la protección de precios resultantes de la competencia, la causalidad se convierte en un

6 Strafrecht, AT, $3^{\text {a }}$ edición 1997, p. 18. 
elemento difícilmente perceptible y dependiente de una prueba pericial cuya interpretación y valoración en modo alguno resulta fácil. Ello suele impulsar al Legislador a convertir muchos de esos tipos penales en delitos de peligro abstracto (caso del art. $284 \mathrm{CP}$, abuso de mercado) es decir, a prescindir de la producción de un resultado lesivo, para facilitar su aplicación.

Bajo estas condiciones las cuatro consecuencias del principio de legalidad (lex praevia, prohibición de aplicación retroactiva de la ley, lex scripta, exclusión del derecho consuetudinario de las fuentes del derecho penal, lex certa, exigencia de determinación precisa de la materia de la prohibición o del mandato de acción, y lex stricta, prohibición de extensión analógica de la ley), tienen especiales dificultades, pues han sido desarrolladas preferentemente en relación a delitos "visibles", es decir, sensorialmente perceptibles, que tienen un determinado "cuerpo del delito" en el sentido de las leyes procesales tradicionales (p. e. arts. 334 y ss. de la LECr española de 1882).

Es decir, en este ámbito, es frecuente que los tipos penales no estén basados en "un suceso del mundo sensible en el que, una acción voluntaria, en un determinado lugar y en un tiempo determinado, produce una modificación sensible en personas individuales o en una cosa" como suponía $v$. Liszt $^{7}$ que ocurría en todos los delitos. Este prototipo clásico del delito se caracterizaba, por regla general, por tipos penales que se suponían estructurados sobre la base de un conjunto de elementos reconocidos a través de resultados materiales y de medios que dejan rastros sensibles de su utilización (heridos, muertos, lesiones, huellas digitales, manchas de sangre, de pólvora, arma que permitió el disparo, fractura de paredes, ventanas, etc.) y, por lo tanto perceptibles por los sentidos.

Por el contrario, el abuso de los poderes del administrador desleal o el tipo del blanqueo de dinero (art. 301. 1 CP), por ejemplo, no tiene un objeto en el que se debe manifestar un daño material sensible en el sentido tradicional de la ya citada teoría del "cuerpo del delito", producido por la infracción de la prohibición. El "cuerpo" de estos delitos no son rastros sensibles, sino acciones o documentos que no se diferencian externamente de otros en los que se han registrado operaciones financieras, a veces, difícilmente diferenciables de las legales; su significación penal no está condicionada por una percepción sensorial, sino por una ponderación e interpretación de los hechos. Dicho de otra manera: en tales tipos penales el equilibrio estimado necesario para la seguridad jurídica entre la descripción y la valoración, entre elementos descriptivos y normativos, está notablemente modificado.

La cuestión es especialmente problemática en ciertos delitos del Código Penal español en los que el legislador agota el contenido del tipo en elementos normativos. Me refiero al ejemplo más llamativo, al caso del artículo $291 \mathrm{CP}$

7 Strafrechtliche Vorträge und Aufsätze, I, 1905, p. 241. 
español que sanciona con prisión de seis meses a tres años y multa de hasta el triplo del beneficio obtenido a los que "prevaliéndose de su situación mayoritaria en la junta de accionistas o el órgano de administración de cualquier sociedad (...) impusieren acuerdos abusivos, con ánimo de lucro propio o ajeno, en perjuicio de los demás socios, sin que reporten beneficios a la misma". Brevemente, la acción típica es abusar del derecho de la mayoría. La noción de abuso del derecho, una creación de la jurisprudencia francesa en materia civil, es ya problemática en el derecho privado, ámbito en el que no faltan quienes rechazan su aplicación por su carácter difuso. Su reducida capacidad descriptiva hace mucho más dudosa todavía su utilización en el derecho penal.

Lo mismo ocurre en el delito de "falseamiento de las cuentas anuales de una sociedad" (art. $290 \mathrm{CP}$ ), en el que el legislador también ha preferido una formulación de reducida capacidad descriptiva, que nos obliga a distinguir entre la conducta típica y la socialmente adecuada comprobando si las cuentas anuales reflejan la imagen económica fiel de la empresa, cuestión que se resiste a ser definida con precisión y que, dogmáticamente, solo puede ser considerada como una imagen relativamente fiel de la empresa, como subrayan diversos autores $^{8}$. La alternativa, representada por el modelo del artículo 2621 de Codice Civile italiano, hubiera sido más respetuosa con la exigencia de determinación deducida del principio de legalidad, puesto que en ese artículo la acción típica es descripta como la exposición en el balance o en las comunicaciones sociales de hechos inveraces sobre la constitución o sobre las condiciones económicas de la sociedad, o como el ocultamiento en todo o en parte de hechos concernientes a las mismas?

Esta problemática no es nueva. Con razón sostuvo Peters en 1961 respecto de esta cuestión, que "si se quiere abarcar en el tipo la ilicitud grave, es necesario darle una formulación que, indirectamente, alcanzará también ilicitudes que no son auténticamente criminales o que pueden ser extendidas interpretativamente a ilícitos no criminales" ${ }^{\prime 10}$. Esto es lo ocurrido con el delito de blanqueo de dinero europeo, cuya amplitud permitió al Tribunal Supremo Federal alemán afirmar en su sentencia de 4.7.200111 que "el abogado defensor que acepta un honorario, que sabe proveniente de un delito, puede ser punible por blanqueo de dinero del $\S 261$ StGB”. El Tribunal Constitucional Federal alemán ${ }^{12}$ ha sido más exigente con el Legislador y estableció que el tipo del § 261 StGB solo resultará compatible con el derecho constitucional a ser defendido por un abogado de la elección del inculpado, si se requiere que el Defensor hubiera

\footnotetext{
8 Confr. E. Bacigalupo, Teoría y Práctica del Derecho Penal, tomo 2, pp. 1226 y ss.; K. Tiedemann, Wirtschaftsstrafrecht und Wirtschaftskriminalität, 2, 1976, p. 146.

9 Confr. al respecto: L. Foffani, en C. Pedrazzi, A. Alessandri, L. Foffani, S. Seminara, G. Spagnolo, Manuale di diritto penale dell'impresa, $2^{\text {a }}$ edición, 1998, pp. 240 y ss.

10 Festschr. für Eb. Schmidt, 1961, pp. 488 y ss. (494).

11 BGHSt, 47, 68 y ss.

12 BVerfG, sentencia de 30.3.2004, en NJW 2004, pp. 1305 y ss
} 
tenido al recibir el honorario un conocimiento seguro del origen del dinero. Dicho de otra manera, excluyó el dolo eventual respecto de la procedencia del dinero de un delito. A ello agregó, con razón, que el abogado "no está obligado a investigar sobre la legalidad o ilegalidad de la fuente de ingresos de su mandante".

Peters señaló también, acertadamente, que el Legislador se encuentra ante un dilema: o bien construye los tipos penales de una manera muy determinada, asumiendo que ilicitudes graves pueden quedar fuera del tipo y, de esta manera, sacrifica su pretensión de justicia, con lo cual producirá una disminución de la confianza en el poder penal del Estado, o bien se decide por formulaciones amplias, dando lugar a una sensible perturbación en el campo de la acción individual, dado que abarcará acciones respecto de las cuales el reproche jurídico penal no es adecuado ${ }^{13}$. Lamentablemente, lo cierto es que los Legisladores, por lo general, se deciden por formulaciones amplias, cuya concreción queda en manos de los tribunales.

Esta decisión traslada a la judicatura una responsabilidad particular, los tribunales deben definir, al tiempo de aplicar la ley, los elementos del tipo que el legislador no ha podido concretar o no ha creído conveniente concretar más. Ello da lugar a una notable transformación de los problemas de la lex certa en cuestiones de lex stricta, es decir, en una transferencia de la responsabilidad originaria del legislador hacia los tribunales, lo que acuerda, además, una especial significación a la prohibición de la analogía en la interpretación judicial.

Precisamente de las alternativas señaladas por Peters se deriva la importancia del principio de determinación. Es necesario que la ley penal (objetivamente considerada) permita al ciudadano saber qué conducta está prohibida y que la definición de esa conducta no quede totalmente en manos del juez. En este último aspecto se pone de manifiesto la conexión existente entre principio de determinación y la exigencia de ley previa. Resulta evidente que en los delitos dolosos una determinación del contenido de la ilicitud por parte del Juez indica que la ley, en el sentido de ley de contenido determinado, no "existió" hasta el momento de su concreción judicial y que, por ello, sería conceptualmente difícil considerarla como una ley previa.

Esta problemática ha sido recientemente abordada de manera implícita por el Tribunal Constitucional Federal Alemán en su sentencia de 23 de junio de 2010. Esta sentencia es especialmente instructiva, toda vez que compendia las cuestiones del principio de legalidad a propósito de la constitucionalidad de los tipos de la administración desleal, previstos en el §266 StGB ${ }^{14}$.

\footnotetext{
13 Ibídem, pp. 494 y ss.

14 El $\$ 266$ StGB prevé dos tipos de administración desleal, designados como el tipo del “abuso" y el tipo de la "deslealtad”; confr. Schönke/Schröder, U. Kindhäuser, StGB, 3ª edición; P. Wittig, en B.von Heintschel- Heinneg, StGB, 2010, \266, 6 y ss.
} 
La constitucionalidad de los tipos penales de la administración desleal, provenientes de la reforma legal de 26 de mayo de 1933, había sido puesta en duda desde hacía tiempo. El Tribunal Supremo del Reich (Reichsgericht) había considerado que el Legislador había renunciado a vincular a los tribunales a "rígidos conceptos jurídicos" 15 . No faltaron quienes sostuvieron que ello permitía una saludable "extensión del tipo en el sentido de las concepciones nacional-socialistas"16. En los últimos tiempos el BGH había sostenido que la constitución por los administradores de cajas negras comporta una puesta en peligro del patrimonio administrado equivalente a un daño patrimonial, aunque no se haya producido una disminución del mismo. La enunciación muy general de los deberes del administrador respecto del patrimonio administrado en el texto de ese parágrafo y la amplitud del concepto de perjuicio requerido por los tipos de la administración desleal dieron lugar al planteamiento de la cuestión constitucional.

El BVerfG subrayó en esta sentencia que el mandato de determinación precisa de la ley no requiere que el Legislador deba servirse exclusivamente de elementos típicos descriptivos. Pero aclaró que "el grado de determinación legal de los tipos individuales no puede ser establecido en general" y que por ello, "la decisión, de si el Legislador ha cumplido con su deber respecto del principio de legalidad, debe ser alcanzada mediante "una consideración total valorativa, observando las posibles alternativas de regulación"17. El Tribunal destacó especialmente el deber de los jueces de "no contribuir -mediante alejadas interpretaciones o un entendimiento de la norma carente de claros contornos- a elevar las inseguridades existentes sobre el ámbito de aplicación de una norma, alejándose todavía más de la finalidad del artículo 103.2 GG”, que contiene el principio de legalidad. En este sentido, la sentencia comentada señaló el deber de los jueces de precisar y concretar, en lo posible, mediante la interpretación, el ámbito de aplicación de las normas penales y, en el mismo sentido, el elevado control sobre esas interpretaciones que debe ejercer la jurisdicción constitucional.

Ello es correcto. Pero deberíamos precisar que tipos penales que solo definen la conducta típica mediante un elemento normativo, sin especificar las circunstancias fácticas del hecho, constituyen, en realidad, auténticas cláusulas generales, incompatibles con el mandato de determinación precisa ${ }^{18}$. Ya lo había indicado Welzel: "La columna vertebral de la ley del Estado de Derecho, reside en la descripción típica proporcionando las circunstancias del hecho ( $A n-$

y 25 y ss.

15 RGSt, 69, 58 (62).

16 Confr. Bruns, Die Befreiung des Strafrechts vom zivilistischen Denken, 1938, citado en la sentencia del BVerfG de 23.6.2010, párrafo 16.

17 Párrafos 73 y 74 de la citada sentencia.

18 Confr. E. Bacigalupo, Teoría y Práctica del Derecho Penal, tomo 2, 2009, pp. 1241 y ss. 
gabe der Tatumstände) y de los elementos de la autoría"19. WELzEL consideraba que no cumplen con la exigencia de precisa determinación formulaciones como "poner en peligro importantes intereses públicos" o "infringir el orden público" 20 . Parece claro que la razón de ser de este punto de vista es la excesiva preponderancia de los elementos normativos en la configuración del tipo penal.

\section{-III-}

En el ámbito del derecho penal económico es preciso tratar problemas particulares del principio de legalidad de este subsistema normativo. Comenzaré por una característica muy señalada del derecho penal económico: el frecuente recurso del legislador a las leyes penales en blanco ${ }^{21}$. La penalización de ámbitos regulados por normas reglamentarias solo es posible en la medida en la que por medio de una ley en sentido formal sean incriminadas como delito las infracciones reglamentarias. Este fenómeno, que no es una exclusividad del derecho penal económico, se explica cuando la autoridad competente para dictar el reglamento o la norma complementaria (por lo general el Poder Ejecutivo o una autoridad administrativa especialmente autorizada) carezca de competencia para sancionar leyes en sentido formal. Esta situación se observa especialmente en el ámbito del derecho penal del medio ambiente, en el que el artículo 325 del Código Penal español hace expresa referencia a la infracción de "leyes o disposiciones de carácter general protectoras del medio ambiente".

En ocasiones se ha sostenido que las leyes penales en blanco serían contrarias al principio de legalidad. Sin embargo, el principio de legalidad requiere básicamente que la conducta esté amenazada con pena antes de la comisión del delito. Si esa conducta consiste en la infracción de un precepto de una ley no penal o de una disposición que no tiene la jerarquía normativa de ley, las exigencias del principio de legalidad estarán de todos modos cubiertas ${ }^{22}$.

Una cuestión de especial interés en esta materia, en la que los complementos normativos de carácter reglamentario suelen ser cambiantes por su adecuación a normas técnicas, es la referente a la posible aplicación retroactiva del complemento de una ley penal en blanco más favorable al acusado. Piénsese, por ejemplo, en la reforma de un reglamento interpretativo de una ley fiscal que permita, a partir de su publicación, excluir de la cuota debida de un impuesto, conceptos que al tiempo de la comisión del delito fiscal no eran deducibles, de tal manera que el hecho, con la nueva disposición reglamentaria, ya no sería delito fiscal. Otro ejemplo: una nueva reglamentación administrativa de determinadas emisiones permite superar los niveles que al tiempo de la comisión del delito eran punibles.

\footnotetext{
19 Das Deutsche Strafrecht, 11ª edición, 1969, p. 23.

20 Ibídem.

21 Confr. E. Bacigalupo, Teoría y práctica del derecho penal, 2009, tomo 1, pp. 385 y ss.

22 Confr. STC 127/90, en favor de la constitucionalidad.
} 
La cuestión podría tener dimensión constitucional y probablemente la tendrá en un futuro cercano. Los derechos penales nacionales han reconocido, por regla, que la ley penal más favorable tiene carácter retroactivo y beneficia al acusado (por ejemplo: Código Penal alemán, parágrafo 2 (3); Código penal austriaco, parágrafo 61; Código Penal francés, art. 112-1; Código Penal español, art. 2.2; Código Penal italiano, art. 2; Código Penal portugués, art. 2.4; Código Penal suizo, art. 2 (2)). El derecho español es más amplio que otros, pues impone la retroactividad de la ley más favorable, inclusive de las dictadas durante la ejecución de una condena firme. Sin embargo, la retroactividad llamada benigna tradicionalmente no era considerada de rango constitucional. En España el art. 9.3 CE permite, pero no impone, que las leyes penales más favorables sean retroactivas.

Diferente es la situación en América como consecuencia de lo establecido por el artículo 9 del Pacto de San José de Costa Rica de 1969, que ha reconocido la retroactividad de la ley penal más favorable como un derecho fundamental.

La situación europea parece anunciar un cambio respecto de la posición tradicional en esta materia que va en la misma dirección y que personalmente valoro como positivo. El Proyecto de Tratado sobre una Constitución para Europa de 2005 no ha sido aprobado, pero pone de manifiesto el estado de la opinión jurídica. En este sentido, el Proyecto propone constitucionalizar la retroactividad de las leyes penales más favorables (art. II-109 (1), recogiendo el artículo 49.1 de la Carta de Derechos de Niza de 7 de diciembre de 2000. De todos modos, este principio solo sería aplicable respecto del derecho comunitario; no sería una norma que, por ahora, afecte a los derechos nacionales de los EE MM (art. II-111).

Una vez aclarada la dimensión constitucional del problema podemos tratar la problemática de la retroactividad de las leyes o reglamentos integrantes de una ley penal en blanco más favorables al acusado. Las opiniones están divididas. La antigua jurisprudencia española fue contraria en un principio a la aplicación retroactiva del complemento normativo más favorable, como es posible ver en la STS de 31.1.1871. Pero, a partir de las sentencias de 8.11.1963 y 25.9.1985, el Tribunal Supremo ha considerado, en general, que las disposiciones administrativas llamadas a completar una ley penal en blanco, que determinan una situación penalmente más favorable para el acusado o, en su caso, el condenado, deben ser aplicadas retroactivamente ${ }^{23}$.

La doctrina y la jurisprudencia alemana, por el contrario, se muestran divididas respecto de esta cuestión. Una parte de la misma sostiene que es necesario dis-

23 Confr. E. Bacigalupo, Principios de Derecho Penal, citado, p. 104. En cuestiones análogas, como el aumento de las cuantías en los delitos contra la propiedad o el patrimonio, la antigua jurisprudencia ha sido vacilante: confr. J. R. Casabó Ruiz, en Córdoba Roda/ R. Mourullo/ Toro Marzal/ Casabó Ruiz, Comentarios al Código Penal, II, 1972, pp. 56 y ss. 
tinguir según la finalidad de la norma penal. Es decir: según que la norma penal tenga la finalidad de asegurar la obediencia de la norma integradora o el efecto de esta ${ }^{24}$. En el primer caso, finalidad de asegurar la obediencia a la norma complementaria, se considera que rige la prohibición de aplicación retroactiva de la disposición integradora desfavorable al acusado, pues en el momento del hecho no era posible obedecer a una norma todavía inexistente. Por el contrario, en el segundo caso, es decir cuando lo que se quiere asegurar es el efecto de la norma integradora, consideran los defensores de esta tesis que no regiría el mandato de aplicación retroactiva de la ley más favorable.

Otra parte importante de la teoría, representada por Hassemer, se opone a esta conclusión - a mi modo de ver con razón-, sosteniendo que lo decisivo es la comparación de la "situación jurídica total" existente en el momento de la comisión del hecho y el momento de la sentencia ${ }^{25} \mathrm{y}$, en el caso de España, de la ejecución. Por lo tanto, si la modificación de la norma que integra la ley penal en blanco determina una situación jurídica más favorable al acusado que la del momento de comisión del delito, deberá serle aplicada retroactivamente.

Una cuestión análoga a la recién tratada es la de la retroactividad de la jurisprudencia más favorable al acusado, cuestión especialmente importante en los derechos de tradición española, en los que la ley posterior más favorable se aplica inclusive durante la ejecución de la pena (por ejemplo: CP español, art. 2०.2; CP chileno, art. $18 \mathrm{CP}$, argentino, art. 2 (2); CP brasileño, art. 2; CP panameño, art. 14; CP peruano, art.6; CP uruguayo, art. 15 (2); diverso: CP paraguayo, art. 5; pero el art. 14 de la Constitución prevé la retroactividad más favorable inclusive para el condenado). La cuestión tiene, ciertamente, un alcance general, pero en la práctica puede ser frecuente en el ámbito de delitos fiscales $^{26}$.

Una parte de la teoría niega que la prohibición de aplicación retroactiva de las leyes penales alcance a la jurisprudencia, "pues -se dice- la nueva interpretación de la ley no tiene el sentido de una sanción o agravación retroactiva, sino el de la realización de una voluntad de la ley que siempre existió" 27 . Consecuentemente, se postula que un cambio jurisprudencial desfavorable para el acusado sea aplicable aunque haya tenido lugar después del momento de comisión del delito.

Otro sector, al que me adhiero ${ }^{28}$, sostiene, por el contrario, que el principio de

\footnotetext{
24 Confr. G. Jakobs, Strafrecht, AT, $2^{\text {a }}$ edición, 1992, p. 100.

25 Confr. $W$. Hassemer, en AK-Kommentar, 1, 1990, parágrafo 2 , no 36 y ss.

26 Confr. TS, resolución del pleno de 24.11.1997, en la que se modificó la relación concursal del delito de contrabando (delito fiscal específico) con el de tráfico de drogas.

27 C. Roxin, loc.cit. p.121; B. Schünemann, Nulla poena sine lege?, 1978, pp. 27 y ss.; con reservas A. Eser, en Schönke/ Schröder, StGB-Kommentar, 26 edición, 2001, parágrafo 2, $\mathrm{n}^{\circ}$ 9.

28 Confr. E. Bacigalupo, en Ambito e Prospettive di uno Spazio Giuridico Penale Europeo, editado por S. Moccia, 2004,
} 
protección de la confianza legítima resulta vulnerado tanto por las modificaciones jurisprudenciales, como por las de la legislación ${ }^{29} \mathrm{y}$, por lo tanto, los cambios desfavorables de la jurisprudencia no deberían ser aplicados a los hechos ejecutados con anterioridad. Este punto de vista tiene su apoyo en la tesis que afirma la unidad del texto legal y su interpretación. El texto legal es siempre un texto interpretado y, por lo tanto, una nueva interpretación del texto es equivalente a un nuevo texto. Consecuentemente, no hay ninguna razón para excluir la aplicación de los cambios jurisprudenciales favorables para el acusado.

En este sentido es interesante la versión de Florencia del año 2000 del Corpus Iuris para la protección de los intereses financieros de la $U E^{30}$, que es un proyecto mediante el cual han sido codificados ocho tipos penales en materia fiscal, de corrupción y de malversación, junto con las correspondientes normas de la parte general y del proceso penal para ser aplicados en el ámbito territorial de la Unión Europea. En el marco del principio de legalidad, el Corpus Iuris establece que "les changements d'interprétation ne son admis que s'ils étaint raisonnablement prévisibles".

Sin embargo, reconociendo el sentido positivo de esta regla, lo cierto es que la previsibilidad del cambio solo debería condicionar, en todo caso, la aplicación retroactiva de la jurisprudencia desfavorable. Por el contrario, los cambios jurisprudenciales favorables al acusado no deberían estar sometidos a su previsibilidad, de la misma manera que la aplicación de la ley más favorable no requiere que la nueva ley sea previsible. Desde este punto de vista la limitación introducida en el Corpus Iuris será difícilmente aceptable ${ }^{31}$.

Claro está que la aplicación retroactiva de la jurisprudencia más favorable no es una cuestión pacífica. Como dijimos, esta cuestión tiene un valor práctico muy especial en los países de la familia del derecho español, en los que la retroactividad de la ley más favorable beneficia inclusive a los ya condenados. Sin embargo, la jurisprudencia española, apoyándose en la falta de prescripción legal expresa, se opone a este punto de vista, sin tener en cuenta que la retroactividad de la jurisprudencia favorable al acusado se deduce de su cercanía conceptual con la ley más benigna.

$-\mathrm{IV}$ -

Concluyo con una breve consideración sobre nuevas garantías, complementarias del principio de legalidad. Con razón se ha dicho que las constituciones

pp. 305 y ss. (309 y ss.).

29 U. Neumann, ZStW 101 [1991], pp. 331 y ss. (336, 347 y ss.).

30 Redactado el grupo de expertos designado por la Comisión de la UE (E. Bacigalupo, M. Delmas-Marty, G. Grasso, J. Spencer, D. Spinellis, K. Tiedemann, J. Vervaele, C. Van den Wyngaert)

31 Confr. E. Bacigalupo, en Ambito e Prospettive citado, nota 45, p. 310. 
poco o nada dicen sobre las cuestiones materiales del Estado de Derecho en materia penal ${ }^{32}$.

El principio de legalidad, como lo adelantamos al comienzo, garantiza seguridad jurídica, pero no garantiza ni la proporcionalidad de la pena ni los límites del legislador para criminalizar conductas ${ }^{33}$.

El siglo XXI ha comenzado poniendo de manifiesto la convicción sobre la necesidad de introducir con jerarquía constitucional el principio de proporcionalidad de las penas, que tendría la función de completar tanto el principio de legalidad, como el de culpabilidad en lo que estos principios no pueden garantizar. En Europa pueden ser señalados como hitos de esta tendencia: en primer lugar el ya citado Corpus Iuris para la protección de los intereses financieros de la $U E^{34}$ (versión de Florencia-2000) ${ }^{35}$, la Carta de Derechos de Niza de 2000 (art. 49.3) y, finalmente, el frustrado Proyecto de Tratado Constitucional Europeo (art. II-109, 3). Los tres precedentes revelan una clara tendencia supranacional al reconocimiento del principio de proporcionalidad de las penas.

La incorporación del principio de proporcionalidad a las garantías constitucionales renueva las perspectivas para una reelaboración del sistema de consecuencias jurídicas del derecho penal económico basada en el carácter del derecho penal como ultima ratio de la política social y de la exigencia de protección de bienes jurídicos. Sin duda, la cuestión podría afectar también a la individualización de la pena, de la que, sin embargo, no es posible ocuparnos en esta ocasión ${ }^{36}$.

Aunque la Constitución española no lo menciona expresamente, es evidente que el principio de proporcionalidad forma parte de los principios jurídicos del Estado de Derecho, dado que el artículo $1^{\circ} \mathrm{CE}$ considera que la justicia es uno de los valores superiores del orden jurídico. Es indiscutible, por lo tanto, que la proporcionalidad de la gravedad de la pena respecto de la del delito no es sino una condición mínima de la realización del valor justicia en una situación determinada. De cualquier manera esta cuestión no se ha planteado hasta ahora en España.

Pero, sin perjuicio de ello, la introducción del principio fundamental de la proporcionalidad de las penas podría conducir a una revisión del sistema penal

\footnotetext{
32 Confr. W. Naucke, Strafrecht, Eine Einführung, $3^{\text {a }}$ edición, 1980, p. 95.

33 Sólo excepcionalmente el principio de proporcionalidad ha sido empleado como fundamento de especiales conclusiones: confr. H.-L. Günther, Strafrechtswidrigkeit und Strafunrechtsausschluss, 1983, pp. 210 y ss.

34 Elaborado por : E. Bacigalupo, M. Delmas Marty, G. Grasso, J. Spencer, D. Spinellis, K. Tiedemann, J. Vervaele, C. van den Wyngaert.

35 Confr. M. Delmas-Marty/J. Vervaele (editores), La Mise en Ouvre du Corpus Iuris dans les Etats Membres, p. 189.

36 Confr. B. Schünemann, en Tatproportionalität, edit. Por W. Frisch/A. von Hirsch/H-J. Albrecht, 2003 ,pp. 185 y ss.
} 
vigente, que como dijo Eberhard Schmidt", permite que "nuestra justicia esté enferma de una utilización demasiado amplia de la pena en general y, especialmente, de un despilfarro sin sentido de la pena privativa de la libertad". Deberíamos reflexionar sobre la flexibilización del sistema penal, apoyado esencialmente en la pena privativa de la libertad, para permitir a los tribunales una adecuación de las penas mejor proporcionada a la gravedad del delito. En particular en el ámbito del derecho penal económico y de los delitos patrimoniales, pero no solo en ellos, se podrían lograr seguramente mejores resultados.

Es preciso advertir que no se trata de bagatelizar el derecho penal económico, ni de privilegiar a la delincuencia económica respecto de otras formas de delincuencia. Tampoco se trata de reemplazar las penas privativas de la libertad previstas para los delitos económicos. La cuestión es otra, un programa político criminal moderno no debería continuar centrado en la pena privativa de la libertad y tendría que admitir como penas alternativas, también en el ámbito del derecho penal económico, junto a las penas privativas de la libertad, la multa, la inhabilitación para el ejercicio de las actividades económicas en las que se cometió el delito (por un tiempo no menor al máximo previsto para la pena privativa de la libertad) y la publicación de la sentencia en forma conjunta. Así los tribunales podrían individualizar las penas de una manera más proporcionada a la gravedad del delito y a la culpabilidad del autor.

He dicho Señor Rector.

37 En la introducción a la reedición de 1952 del Proyecto de Código Penal de Gustav Radbruch de 1922, p. IX. 